\title{
Myocardial bridge analysis by multidetector computed tomography and its association with coronary atherosclerosis
}

\author{
Islam Shwaky Abd Elaziz ${ }^{1}$, Mansour Mohamed Sallam ${ }^{\text {, }}$ \\ Mohamed Abo mandour Mousa ${ }^{1}$, Ahmed Raouf Nawar ${ }^{2}$
}

1- Department of Cardiology, Faculty of Medicine, Al-Azhar University, Egypt,2-Department of Cardiology, Denshal Teaching Hospital, Egypt

Corresponding Author: Ahmed Raouf Nawar, Phone: 01099922821, email: ahmedraouf788n@gmail.com

\begin{abstract}
Background: myocardial bridge is still a major public health problem despite the impressive stride in diagnosis and management. Furthermore, the early and accurate diagnosis with the proper management is an important challenge. The determination of the prevalence of myocardial bridges and their location and morphology is extremely important for the prediction of potential complications which are likely to cause greater myocardial damage. Aim of the work: this study aimed to assess noninvasively by using MDCT the presence of atherosclerotic plaques in relation to myocardial bridge coronary segments and to determine the prevalence of myocardial bridges and their morphology (length, depthand diameter) and location. Methods: this was a prospective observation study that was done from June 2017 to April 2018 and included 52 patients presented to the Coronary Care Unit at Al-Azhar University Hospital with stable angina. All patients were subjected to: thorough history taking, full clinical examination, surface ECG, treadmill stresses ECG and do MDCT scan to detect of the presence of myocardial bridge: as regard site, length, depth and degree of systolic obstruction, coronary plaque assessment. Results: among the 52 patients we found that 23 patients had MB and coronary plaque included in group A, 29 patients had MB without coronary plaque included in groupB, In group A, MB was in Mid LAD in 18(78.3\%) patients, Distal LAD in 5(21.7\%) patients, the mean depth of MB was $3.89 \pm 1.75 \mathrm{~mm}$, the mean length of $\mathrm{MB}$ was $22.16 \pm 9.44 \mathrm{~mm}$, the mean degree of systolic obstruction of MB was $61.65 \pm$ $19.47 \%$. While, in group B mid LAD in $20(69.0 \%)$ patients, distal LAD in $7(24.1 \%)$ patients and proximal LAD in $1(3.4 \%)$ patients, distal RCA in $1(3.4 \%)$ patient, the mean depth was $2.83 \pm 1.54 \mathrm{~mm}$ $(\mathrm{p}=0.017)$, the mean length was $22.22 \pm 13.55 \mathrm{~mm}$, the mean degree of systolic obstruction was is $41.72 \pm 24.94 \%(\mathrm{P}<0.004)$.
\end{abstract}

Conclusion: some anatomic characteristics of myocardial bridge, such as degree of systolic obstruction and depth, may help the development of coronary plaque.

Keywords: Myocardial Bridge, Multidetector Computed Tomography, Coronary Atherosclerosis.

\section{Introduction}

Myocardial bridging an inborn coronary abnormality is defined as an intramural segment of a coronary artery that normally courses epicardially for a varying segment of length ${ }^{(1)}$.Myocardial bridging was first described by Geiringer ${ }^{(2)}$ who reported dissection method on autopsy samples and reported an incidence of $23 \%$ with predominance of myocardial bridges on anterior interventricular artery. According to text (Gray's Anatomy) the anatomical distribution of muscle bridges were classified into two as types: superficial (75\% of cases) ${ }^{(3)}$ or deep (25\% of cases), depending on the thickness of the covering muscle layer ${ }^{(4)}$. Additionally, the superficial type can be further classified as complete or incomplete.

Incidence of Myocardial Bridge
The incidence of MB was reported between 15 to $85 \%$ in autopsy studies ${ }^{(5)}$. The frequency had been reported in angiographic studies varies from 0.5 to $16 \%{ }^{(6)}$. The incidence reached $40 \%$ with the provocation test occurred within coronary angiography ${ }^{(7)}$. This difference between angiography and autopsy series referred to multiple factors including the depth and length of the tunneled artery, with only deeply located coronary artery segments within the ventricular myocardium appearing to be compressed enough during systole to be diagnosied on angiography. Also, the occurrence of atherosclerotic plaques proximal to MB may lead to underdiagnoses ${ }^{(8)}$.

\section{Morphology}


Myocardial bridges difference in size with a length ranging from 4 to $40 \mathrm{~mm}$ by autopsy ${ }^{\left({ }^{(9)}\right.} 8$ - $50 \mathrm{~mm}$ by coronary CT angiography ${ }^{(10)}$ and a width and depth between 1 and $4 \mathrm{~mm}$ by autopsy and $1-3 \mathrm{~mm}$ by coronary CT angiography ${ }^{(\mathbf{1 0})}$ deeper and longer bridges and those that showed higher degrees systolic compression $(0.70 \%)$ were more common in symptomatic patients ${ }^{(9)}$. On coronary CT angiography, the depth and the length of myocardial bridging were common used describe bridges. Overall, a depth of $\mathrm{MB}$ of $\geq 2$ mm was considered deep.

\section{Clinical Impact of Myocardial Bridge:}

In most patients, MB was an incidental finding associated with an good survival rate of $97 \%$ at 5 years ${ }^{(11)}$. Also, it is not totally a benign entity. There was reported relation with myocardial ischemia, arrhythmia, myocardial infarction, and sudden death ${ }^{(12)}$. This systolic milking effect altered coronary flow dynamics within the bridged segments (increased diastolic flow velocity and average flow velocity) may cause impaired coronary flow reserve and ischemia (11). Myocardial bridging was happen in patients with HCM, with a percentage as high as $30 \%$ (13).

\section{Treatment}

For asymptomatic patients, no treatment was indicated. Pharmacologic therapy with Bblockers or non-dihydropyridine calcium channel blockers and antiplatelet agents with the objective of relieving symptoms and signs of myocardial ischemia and/or protecting against the risk of future coronary events ${ }^{(14)}$. Nitrates were contraindicated in patients with myocardial bridging. For patients with severe symptoms refractory to medical treatment and recurrent clinical events, percutaneous or surgical intervention may be considered ${ }^{(15)}$. There was a doubt in using stenting in MB treatment.The goal of surgical therapy was coronary artery bypass grafting to segments distal to the myocardial bridging to increase blood flow to compromised areas, or surgical unroofing of the intramyocardial coronary segment (myotomy).

\section{Coronary Angiography}

The standard method for diagnosing MB was coronary angiography with the typical "milking effect" and a "step down-step up" phenomenon induced by systolic compression of the tunneled part of coronary artery ${ }^{(16)}$. Also, these signs provided little information on the functional impact at the myocardial level. In the presence of a proximal stenosis, myocardial bridging may only be identifiable after PTCA when higher intravascular pressures and reversed hypo kinesis unmask myocardial bridging.

\section{Intracoronary Ultrasonography and} Doppler Evaluation of Myocardial Bridges

The "half-moon phenomenon" was a characteristic IVUS observation ${ }^{(17)}$. It seemed specific for the existence of myocardial bridging in as much as it was only found in tunneled segments, but not in proximal or distal segments or in other arteries. In the presence of a half-moon phenomenon on IVUS, milking can be provoked by intracoronary provocation tests, even if the bridge was angiographically undetectable. In intracoronary Doppler studies, pullback of the Doppler-flow wire frequently revealed a characteristic flow pattern, the "fingertip phenomenon" or "spike-and-dome pattern". This flow pattern had described in the experimental studies and consisted of a sharp acceleration of flow in early diastole followed by immediate marked deceleration and a middiastolic pressure plateau.

\section{MDCT Angiography Evaluation of}

\section{Myocardial Bridge}

MDCT angiography offers advantages over conventional angiography for the determine of myocardial bridging, because it was a noninvasive imaging method that allowed evaluation of the coronary artery lumen, wall and surrounding myocardium it yields information on the length, depth and precise location of atherosclerosis associated with myocardial bridging and the identification of vulnerable coronary plaque.

\section{Patients and Methods \\ Methods}

All patients were subjected to cardiovascular risk factors including: age, sex, smoking history, presence of hypertension, dyslipidemia, diabetes mellitus and family history of CAD.

\section{MSCT coronary angiography:}

MSCT coronary angiographic studies by using MDCT

Patients were fasted for 4-6 hours. Oral Bblocker administered one hour before the scan for those with a heart rate above 65 beats/ minute.

A bolus of $80 \mathrm{ml}$ of intravenous non-ionic contrast (Iopamidol 370) (0.5 - $2.0 \mathrm{~mL} / \mathrm{kg}$, $80 \mathrm{~mL}$ maximum volume) were injected with 
mechanical injector followed by $30 \mathrm{ml}$ saline flush.

\section{MDCT data analysis :}

1. Coronary artery calcium score.

2. Detection of the presence of Myocardial

Bridge: as regard site, length, depth and degree of systolic obstruction.

\section{Coronary plaque assessment.}

\section{Results}

This study was a single-center; randomized prospective, observational study we selected our patients among patients presented to the Damahour Imaging Center (DIC) scan between June 2017 and April 2018 referred to do MDCT scan, all patients with myocardial bridge were selected till we collected 52 patients. With the exception of those with multiple ectopic beats, heart rate greater than 75 beats per minute despite therapy, severe lung disease, renal failure, history of allergic reaction to contrast material, atrial fibrillation, history of $\mathrm{CABG}$ or previous PCI.Among the 52 patients we found 23 patients who had myocardial bridge and coronary artery atherosclerotic plaques included in Group (A) (44.2\%), 29 persons having myocardial bridge without $\mathrm{CAD}$ included in group B (55.8\%).

\section{Patient Demographics and Risk Factors}

patients with atherosclerotic plaque (group A) $(\mathrm{n}=23)$, mean age was $60.61 \pm 10.86$ years ranged from 42.0 to 84.0 years, $56.5 \%$ were males, $65.2 \%$ patients were diabetic, $73.9 \%$ were hypertensive, $69.6 \%$ were dyslipidemic, $47.8 \%$ patients were smokers; $8.7 \%$ had family history of CAD while in myocardial bridge without atherosclerotic lesion group (group B) $(\mathrm{n}=29)$, mean age was $52.48 \pm 9.37$ ranged from 35.0 to 69.0 years., $31 \%$ were males, $24.1 \%$ were diabetics, $65.5 \%$ were hypertensive, $37.9 \%$ were dyslipidemic, $24.1 \%$ were smokers, no one had family history of CAD.

Table 1: comparison between the two studied groups according to demographic data $(n=52)$

\begin{tabular}{|c|c|c|c|c|c|c|c|c|}
\hline & \multicolumn{2}{|c|}{$\begin{array}{l}\text { Total } \\
(n=52)\end{array}$} & \multicolumn{2}{|c|}{$\begin{array}{l}\text { MB + lesion } \\
(\mathbf{n}=\mathbf{2 3})\end{array}$} & \multicolumn{2}{|c|}{$\begin{array}{l}\text { MB } \\
(n=29)\end{array}$} & \multirow[t]{2}{*}{ Test of Sig. } & \multirow[t]{2}{*}{$\overline{\bar{P}}$} \\
\hline & No. & $\%$ & No. & $\%$ & No. & $\%$ & & \\
\hline $\begin{array}{l}\text { Sex } \\
\quad \text { Male } \\
\text { Female }\end{array}$ & $\begin{array}{l}22 \\
30\end{array}$ & $\begin{array}{l}42.3 \\
57.7\end{array}$ & $\begin{array}{l}13 \\
10\end{array}$ & $\begin{array}{l}56.5 \\
43.5\end{array}$ & $\begin{array}{l}9 \\
20\end{array}$ & $\begin{array}{l}31.0 \\
69.0\end{array}$ & $\begin{array}{l}\chi^{2}= \\
3.414\end{array}$ & 0.065 \\
\hline $\begin{array}{l}\text { Age (years) } \\
\text { Min. - Max. } \\
\text { Mean } \pm \text { SD. } \\
\text { Median }\end{array}$ & \multicolumn{2}{|c|}{$\begin{array}{l}35.0-84.0 \\
56.08 \pm 10.76 \\
58.0\end{array}$} & \multicolumn{2}{|c|}{$\begin{array}{l}42.0-84.0 \\
60.61 \pm 10.86 \\
61.0\end{array}$} & \multicolumn{2}{|c|}{$\begin{array}{l}35.0-69.0 \\
52.48 \pm 9.37 \\
53.0\end{array}$} & $\begin{array}{l}\mathrm{t}= \\
2.895^{*}\end{array}$ & $0.006^{*}$ \\
\hline
\end{tabular}

$\chi^{2}$ : Chi square test

t: Student t-test

$\mathrm{p}: \mathrm{p}$ value for comparing between the two groups

*: Statistically significant at $\mathrm{p} \leq 0.05$

Table 2: comparison between the two studied groups according to risk factors $(\mathrm{n}=52)$

\begin{tabular}{|c|c|c|c|c|c|c|}
\hline & \multicolumn{2}{|c|}{$\begin{array}{l}\text { MB + lesion } \\
(\mathrm{n}=\mathbf{2 3})\end{array}$} & \multicolumn{2}{|c|}{$\begin{array}{l}\mathbf{M B} \\
(\mathbf{n}=\mathbf{2 9})\end{array}$} & \multirow[t]{2}{*}{$\overline{\alpha^{2}}$} & \multirow[t]{2}{*}{$\bar{p}$} \\
\hline & No. & $\%$ & No. & $\%$ & & \\
\hline Smoking & 11 & 47.8 & 7 & 24.1 & 3.180 & 0.075 \\
\hline HTN & 17 & 73.9 & 19 & 65.5 & 0.424 & 0.515 \\
\hline DM & 15 & 65.2 & 7 & 24.1 & $8.868^{*}$ & $0.003^{*}$ \\
\hline Dyslipidemia & 16 & 69.6 & 11 & 37.9 & $5.142^{*}$ & $0.023^{*}$ \\
\hline History of myocardial infarction & 2 & 8.7 & 0 & 0.0 & 2.623 & $\mathrm{FE}_{\mathrm{p}}=0.191$ \\
\hline
\end{tabular}

$\chi 2$ : Chi square test

FE: Fisher Exact

$\mathrm{p}: \mathrm{p}$ value for comparing between the two groups

$*$ : Statistically significant at $\mathrm{p} \leq 0.05$ 
Myocardial bridge analysis by multidetector computed tomography and its association...

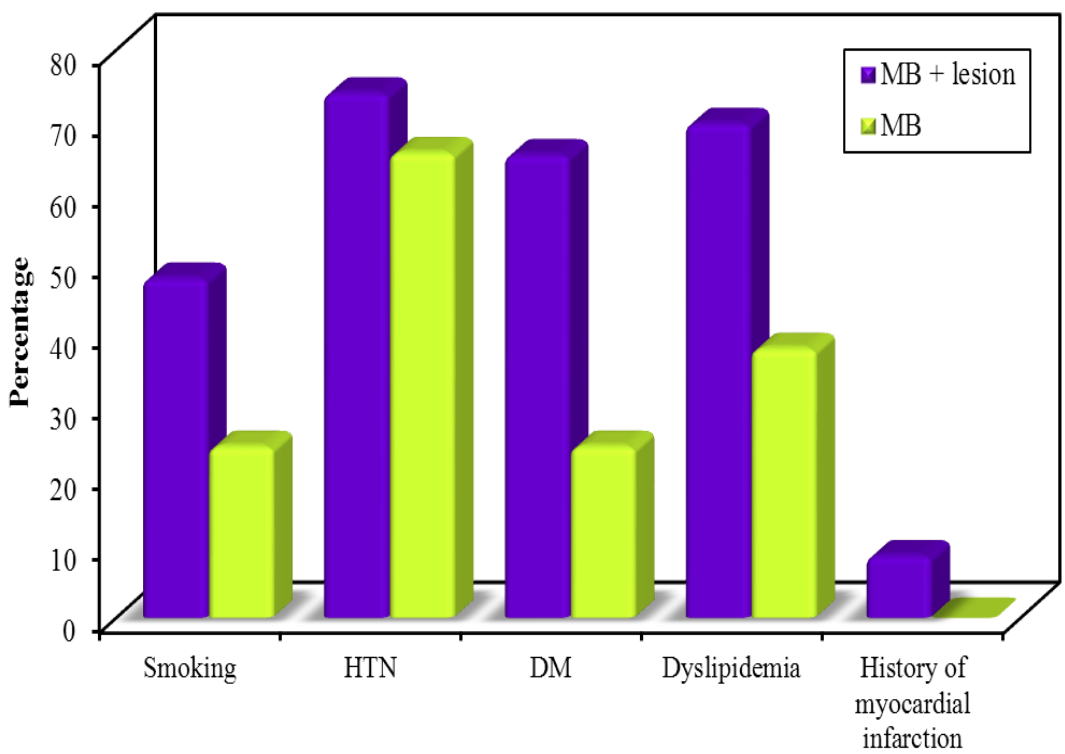

Risk factors

Figure 1: comparison between the two studied groups according to risk factors $(n=52)$

\section{MDCT study:}

In present study, we assessed the myocardial bridge as regards the calcium score, site, length, depth and degree of systolic obstruction.

We found that the mean calcium score in group A was $53.48 \pm 88.89$ and in group B was zero. $(\mathrm{P}<0.001)$. The mean length of $\mathrm{MB}$ in group $\mathrm{A}$ was $22.16 \pm 9.44 \mathrm{~mm}$ and in group B was 22.22 $\pm 13.55 \mathrm{~mm}(\mathrm{P}=0.665)$. The mean depth of $\mathrm{MB}$ in group A was $3.89 \pm 1.75 \mathrm{~mm}$ ranged from 1.80 to $9.50 \mathrm{~mm}$ and in group B was $2.83 \pm 1.54$ $\mathrm{mm}$ ranged from 1.0 to $7.0 \mathrm{~mm}(\mathrm{p}=0.017)$. The mean degree of systolic obstruction of MB in group $\mathrm{A}$ was $61.65 \pm 19.47 \%$ ranged from $10.0 \%$ to $90.0 \%$, and in group B was $41.72 \pm$ $24.94 \%$ ranged from $10 \%$ to $90 \%(\mathrm{P}=<0.004)$. Regarding the group A, MB was in Mid arterial in $18(78.3 \%)$ patients, distal arterial in $5(21.7 \%)$ patients. While in group B, MB was in mid arterial in $20(69.0 \%)$ patients, distal arterial in $8(27.6 \%)$ patients and proximal arterial in $1(3.4 \%)(\mathrm{MCp}=0.857)$

Table 3: comparison between the two studied groups according to calcium score $(\mathbf{n}=52)$

\begin{tabular}{|c|c|c|c|c|c|c|}
\hline & \multicolumn{2}{|c|}{$\begin{array}{l}\text { MB + lesion } \\
(n=23)\end{array}$} & \multicolumn{2}{|c|}{$\begin{array}{l}\mathrm{MB} \\
(\mathrm{n}=29)\end{array}$} & \multirow[t]{2}{*}{ Test of Sig. } & \multirow[t]{2}{*}{$\bar{p}$} \\
\hline & No. & $\%$ & No. & $\%$ & & \\
\hline $\begin{array}{l}\text { Calcium score } \\
0 \\
>0\end{array}$ & $\begin{array}{l}5 \\
18\end{array}$ & $\begin{array}{l}21.7 \\
78.3\end{array}$ & $\begin{array}{l}29 \\
0\end{array}$ & $\begin{array}{l}100.0 \\
0.0\end{array}$ & $\begin{array}{l}\chi^{2}= \\
34.711^{*}\end{array}$ & $<0.001^{*}$ \\
\hline $\begin{array}{l}\text { Min. - Max. } \\
\text { Mean } \pm \text { SD. } \\
\text { Median }\end{array}$ & \multicolumn{2}{|c|}{$\begin{array}{l}0.0-429.0 \\
53.48 \pm 88.89 \\
30.0\end{array}$} & \multicolumn{2}{|c|}{$\begin{array}{l}0.0-0.0 \\
0.0 \pm 0.0 \\
0.0\end{array}$} & $\mathrm{U}=72.50^{*}$ & $<0.001^{*}$ \\
\hline
\end{tabular}

$\chi 2$ : Chi square test

U: Mann Whitney test

$\mathrm{p}$ : $\mathrm{p}$ value for comparing between the two groups

*: Statistically significant at $\mathrm{p} \leq 0.05$ 


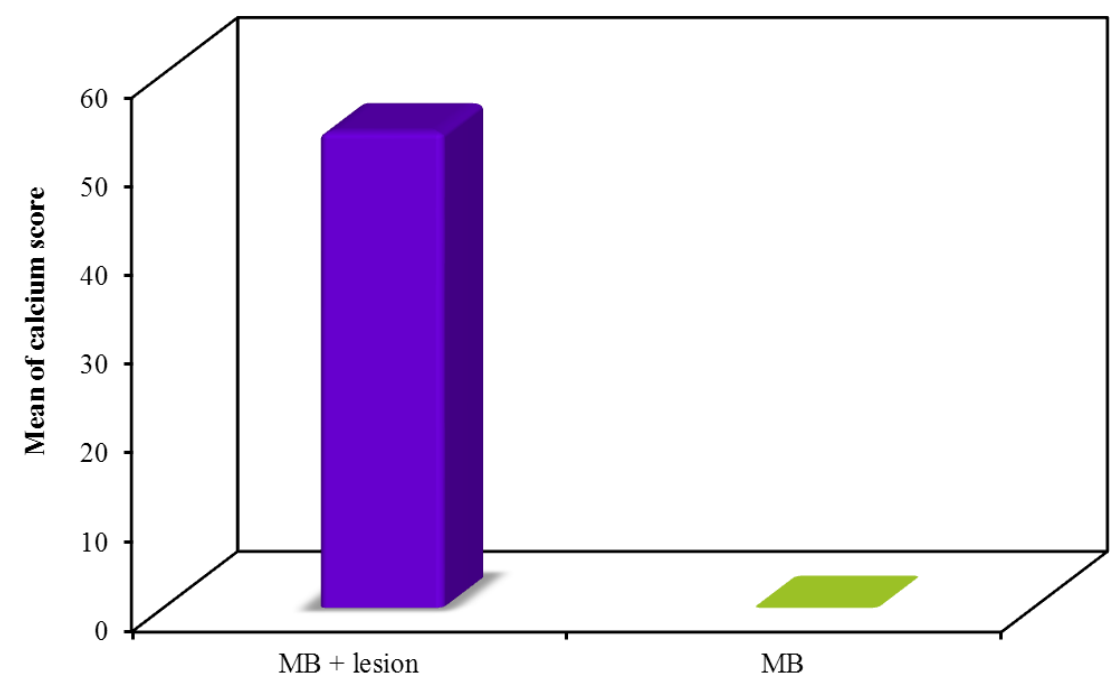

Figure 2: comparison between the two studied groups according to calcium score $(n=52)$

Table 4: comparison between the two studied groups according to site and length of myocardial bridge artery $(\mathbf{n}=52)$

\begin{tabular}{|c|c|c|c|c|c|c|}
\hline & \multicolumn{2}{|c|}{$\begin{array}{l}\mathrm{MB}+\text { lesion } \\
(\mathrm{n}=\mathbf{2 3})\end{array}$} & \multicolumn{2}{|c|}{$\begin{array}{l}\mathrm{MB} \\
(\mathrm{n}=29)\end{array}$} & \multirow[t]{2}{*}{ Test of Sig. } & \multirow[t]{2}{*}{$\mathbf{P}$} \\
\hline & No. & $\%$ & No. & $\%$ & & \\
\hline \multicolumn{7}{|l|}{ Site } \\
\hline Mid & 18 & 78.3 & 20 & 69.0 & $x^{2}=$ & ${ }^{\mathrm{MC}} \mathrm{p}=$ \\
\hline Distal & 5 & 21.7 & 8 & 27.6 & 1.072 & 0.857 \\
\hline Proximal & 0 & 0.0 & 1 & 3.4 & & \\
\hline \multicolumn{7}{|l|}{ Length } \\
\hline Min. - Max. & \multicolumn{2}{|c|}{$4.0-41.60$} & \multicolumn{2}{|c|}{$4.40-68.30$} & $\mathrm{U}=310.0$ & 0.665 \\
\hline Mean \pm SD & \multicolumn{2}{|c|}{$22.16 \pm 9.44$} & \multicolumn{2}{|c|}{$22.22 \pm 13.55$} & & \\
\hline Median & \multicolumn{2}{|l|}{22.0} & \multicolumn{2}{|l|}{20.0} & & \\
\hline
\end{tabular}

$\chi 2$ : Chi square test

FE: Fisher Exact

MC: Monte Carlo

U: Mann Whitney test

$\mathrm{p}$ : $\mathrm{p}$ value for comparing between the two groups

*: Statistically significant at $\mathrm{p} \leq 0.05$

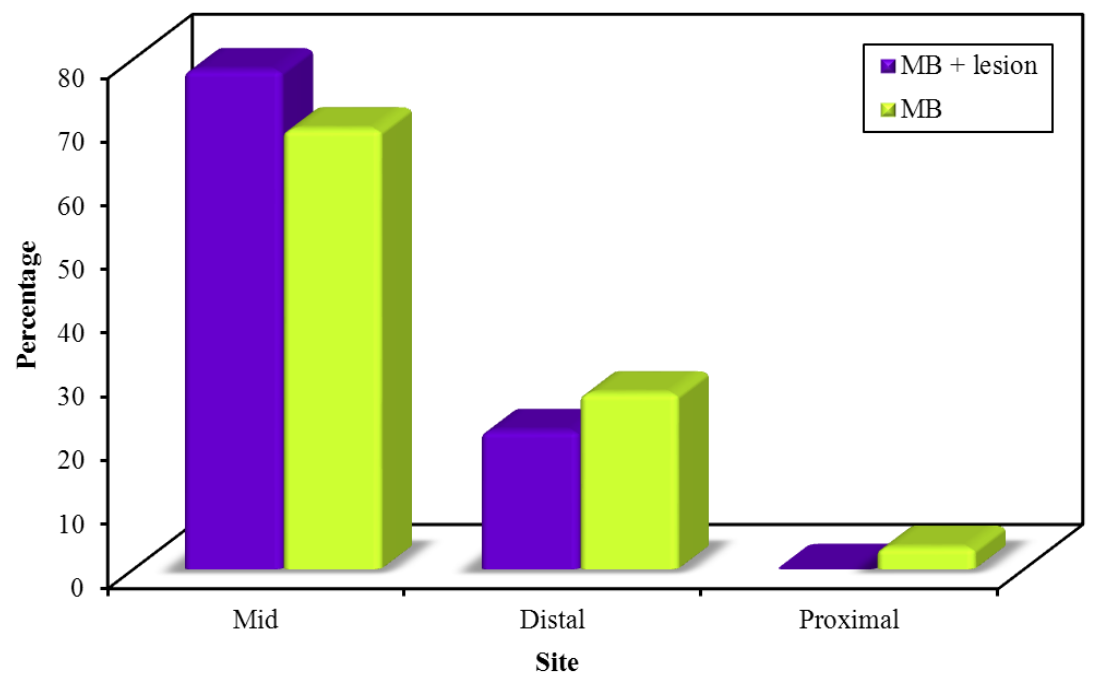

Figure 3: comparison between the two studied groups according to $\operatorname{Site}(n=52)$ 
Myocardial bridge analysis by multidetector computed tomography and its association...

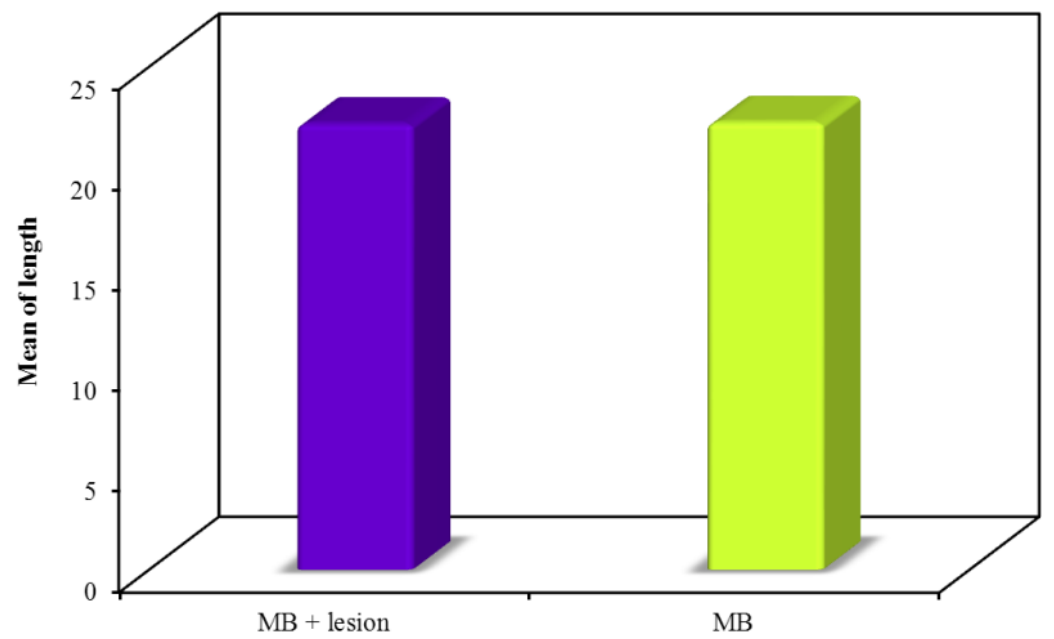

Figure 4: comparison between the two studied groups according to Length $(n=52)$

Table 5: comparison between the two groups according to depth and degree of systolic obstruction

\begin{tabular}{|c|c|c|c|c|c|}
\hline & $\begin{array}{l}\text { Total } \\
(n=52)\end{array}$ & $\begin{array}{l}\text { MB + lesion } \\
(n=23)\end{array}$ & $\begin{array}{l}M B \\
(n=29)\end{array}$ & Test of Sig. & $\mathbf{p}$ \\
\hline & No. & No. $\quad \%$ & \begin{tabular}{|l|l|} 
No. & $\%$ \\
\end{tabular} & & \\
\hline $\begin{array}{l}\text { Depth } \\
\text { Min. - Max. } \\
\text { Mean } \pm \text { SD. } \\
\text { Median }\end{array}$ & $\begin{array}{l}1.0-9.50 \\
3.30 \pm 1.70 \\
3.0\end{array}$ & $\begin{array}{l}1.80-9.50 \\
3.89 \pm 1.75 \\
4.0\end{array}$ & $\begin{array}{l}1.0-7.0 \\
2.83 \pm 1.54 \\
2.20\end{array}$ & $\begin{array}{l}\mathrm{U}= \\
205.50^{*}\end{array}$ & $0.017^{*}$ \\
\hline $\begin{array}{l}\text { Degree systolic obstruction } \\
\text { Min. - Max. } \\
\text { Mean } \pm \text { SD. } \\
\text { Median }\end{array}$ & $\begin{array}{l}10.0-90.0 \\
50.54 \pm 24.59 \\
52.50\end{array}$ & $\begin{array}{l}10.0-90.0 \\
61.65 \pm 19.47 \\
60.0\end{array}$ & $\begin{array}{l}10.0-90.0 \\
41.72 \pm 24.94 \\
35.0\end{array}$ & $\mathrm{U}=178.0^{*}$ & $0.004^{*}$ \\
\hline
\end{tabular}

$\chi 2$ : Chi square test

FE: Fisher Exact

MC: Monte Carlo

U: Mann Whitney test

$\mathrm{p}: \mathrm{p}$ value for comparing between the two groups

*: Statistically significant at $\mathrm{p} \leq 0.05$

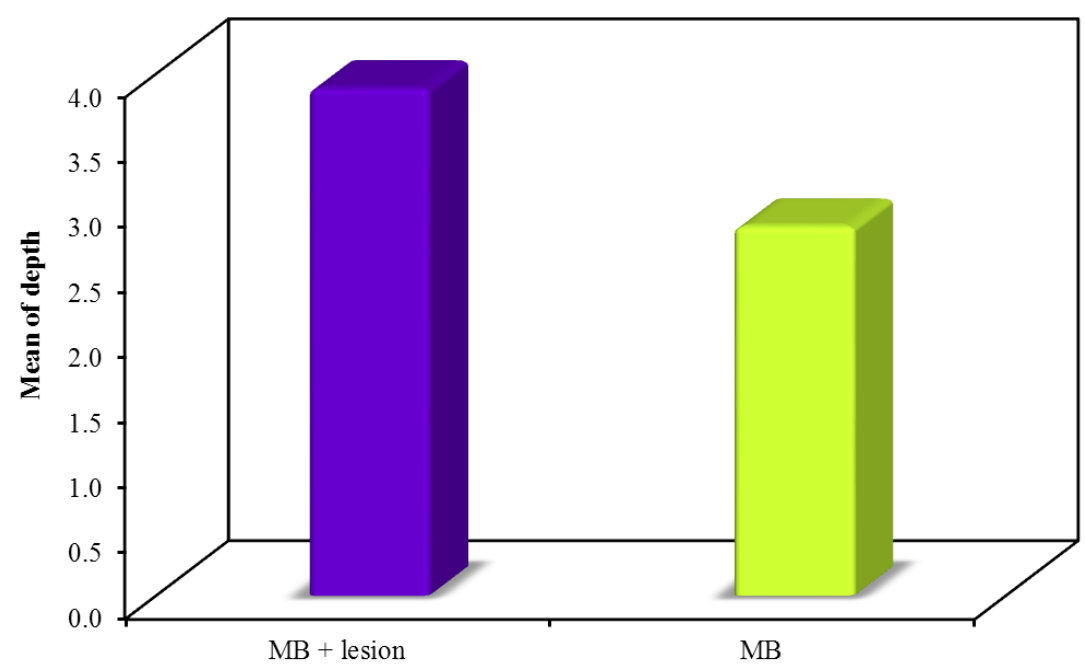

Figure (5): Comparison between the two studied groups according to Depth $(\mathrm{n}=52)$ 


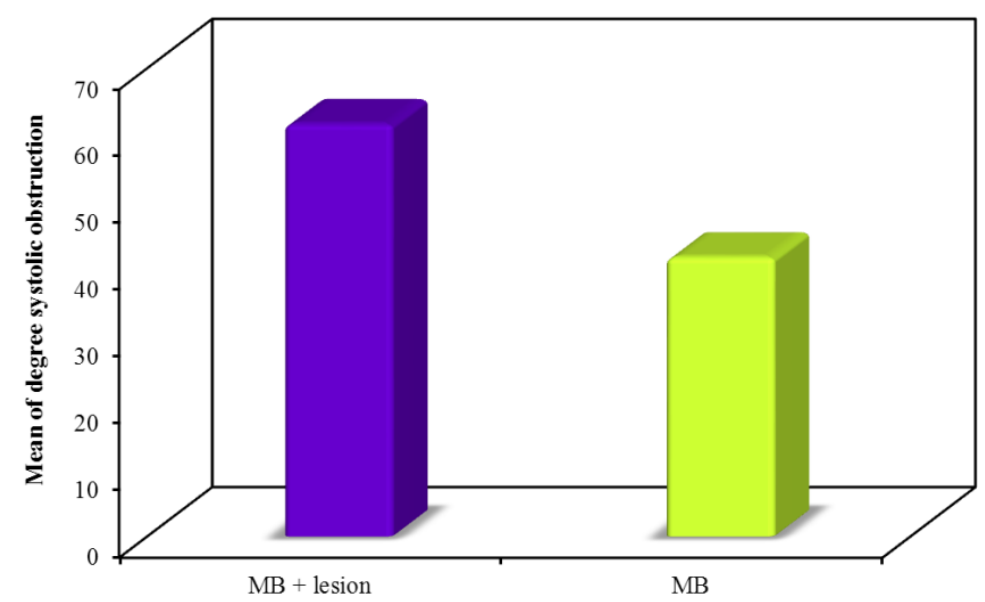

Figure 6: comparison between the two studied groups according to Degree systolic obstruction $(\mathbf{n}=\mathbf{5 2})$

The anatomical distribution of the affected Coronary Artery:

The atherosclerotic plaque in group A was in LAD in 21(91.32\%) of patients, in LM in 1(4.34\%) of patients, in RCA in 1(4.34\%) of patients.

Table 6: distribution of the studied cases according to coronary plaque in MB + Lesion group $(\mathbf{n}=\mathbf{2 3})$

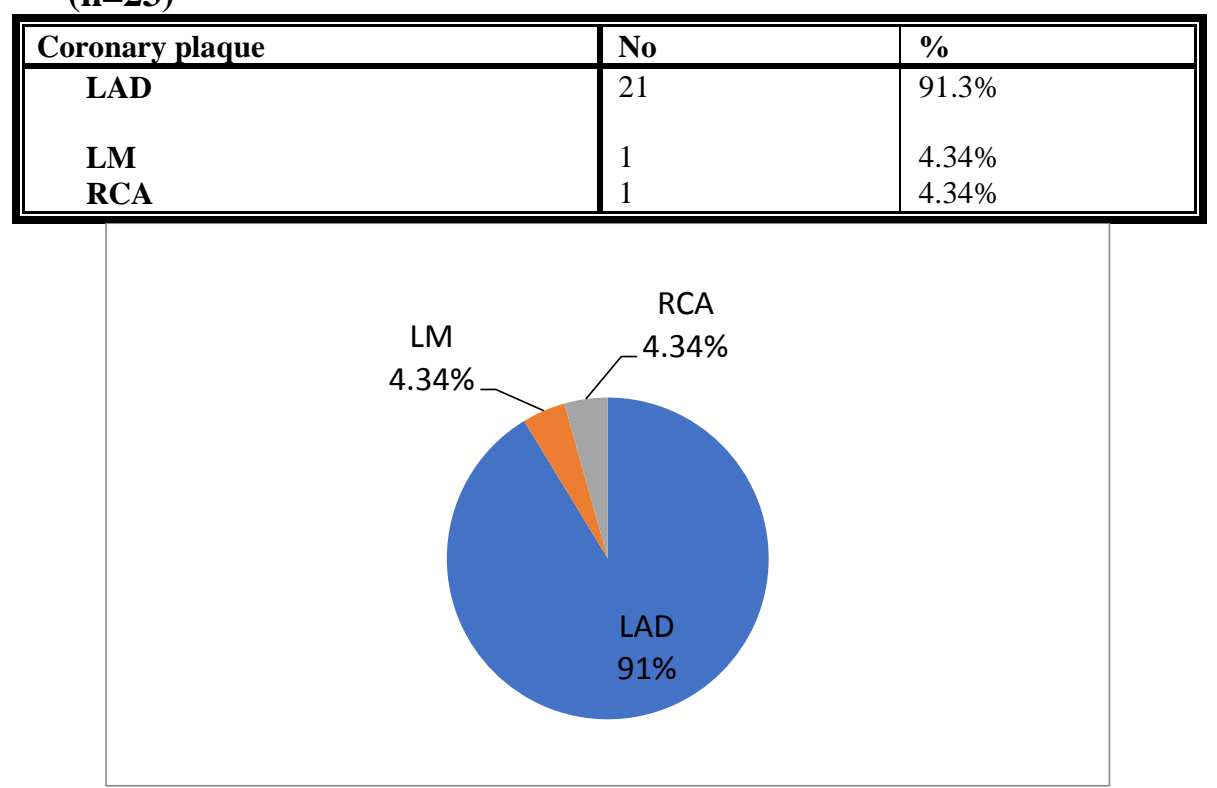

Figure 7: distribution of the studied cases according to coronary plaque in MB + Lesion group $(\mathbf{n}=\mathbf{2 3})$

The site of atherosclerotic plaque:

The atherosclerotic plaque was in mid coronary artery in $3(13.06 \%)$ of patients, in proximal coronary artery in $19(82.6 \%)$ of patients and in the distal coronary artery in $1(4.34 \%)$ of patients.

Table 7: distribution of the studied cases according to segment in $M B+\operatorname{Lesion}$ group $(n=23)$

\begin{tabular}{||l|l|l|}
\hline Coronary plaque & No & $\%$ \\
\hline Proximal & 19 & $82.6 \%$ \\
& & \\
Mid & 3 & $13.06 \%$ \\
Distal & 1 & $4.34 \%$ \\
\hline
\end{tabular}


Myocardial bridge analysis by multidetector computed tomography and its association...

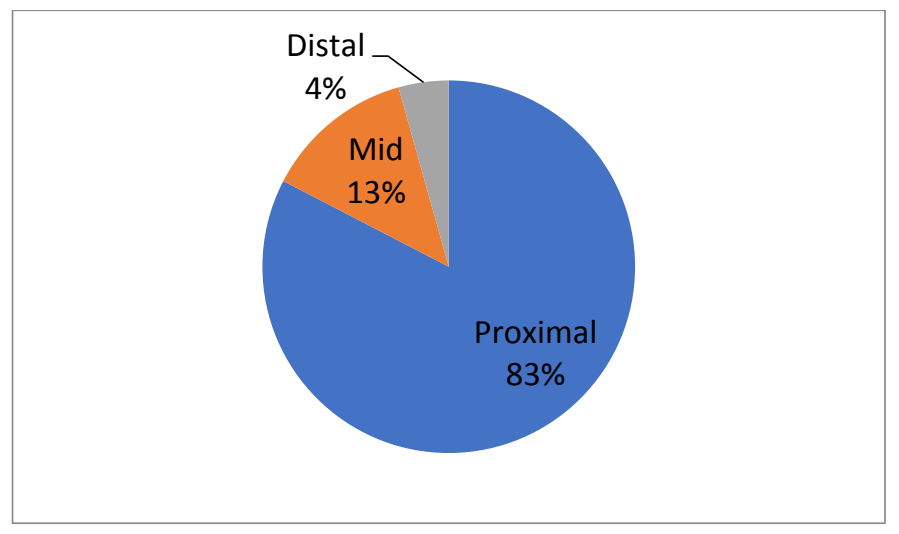

Figure 8: distribution of the studied cases according to segment in $\mathrm{MB}+\mathrm{Lesion}$ group ( $\mathrm{n}=\mathbf{2 3}$ ) Type of coronary plaque:

The atherosclerotic plaque type was LDPV in $8(34.8 \%)$ of patients, MDPV in $13(56.5 \%)$ of patients and HDPV in $2(8.7 \%)$ of patients.

Table 8: $\quad$ distribution of the studied cases in group (A) according to type of coronary plaque $(\mathbf{n}=\mathbf{2 3})$

\begin{tabular}{||l|l|l|}
\hline Coronary plaque & No & $\%$ \\
\hline LDPV & 8 & $34.8 \%$ \\
MDPV & 13 & \\
HDPV & 2 & $56.5 \%$ \\
\hline
\end{tabular}

Figure 9: distribution of the studied cases in group (A) according to type of coronary plaque (n =23)

Distribution of the studied cases in group A according to obstruction:

$5(21.7 \%)$ patients had obstructive coronary plaque with mean $68.0 \pm 13.04$ and range from $60 \%$ to $90 \%, 18(78.3 \%)$ patients had non obstructive coronary plaque with mean $32.22 \pm 7.90$ and range from $20 \%$ to $45 \%$.

Table 9: distribution of the studied cases according to obstruction

\begin{tabular}{||l|l|l||}
\hline Obstruction & $\begin{array}{l}\text { Yes } \\
(\mathbf{n = 5})\end{array}$ & $\begin{array}{l}\text { No } \\
(\mathbf{n = 1 8})\end{array}$ \\
\hline Min. - Max. & $60.0-90.0$ & $20.0-45.0$ \\
Mean \pm SD. & $68.0 \pm 13.04$ & $32.22 \pm 7.90$ \\
Median & 60.0 & 30.0 \\
\hline
\end{tabular}




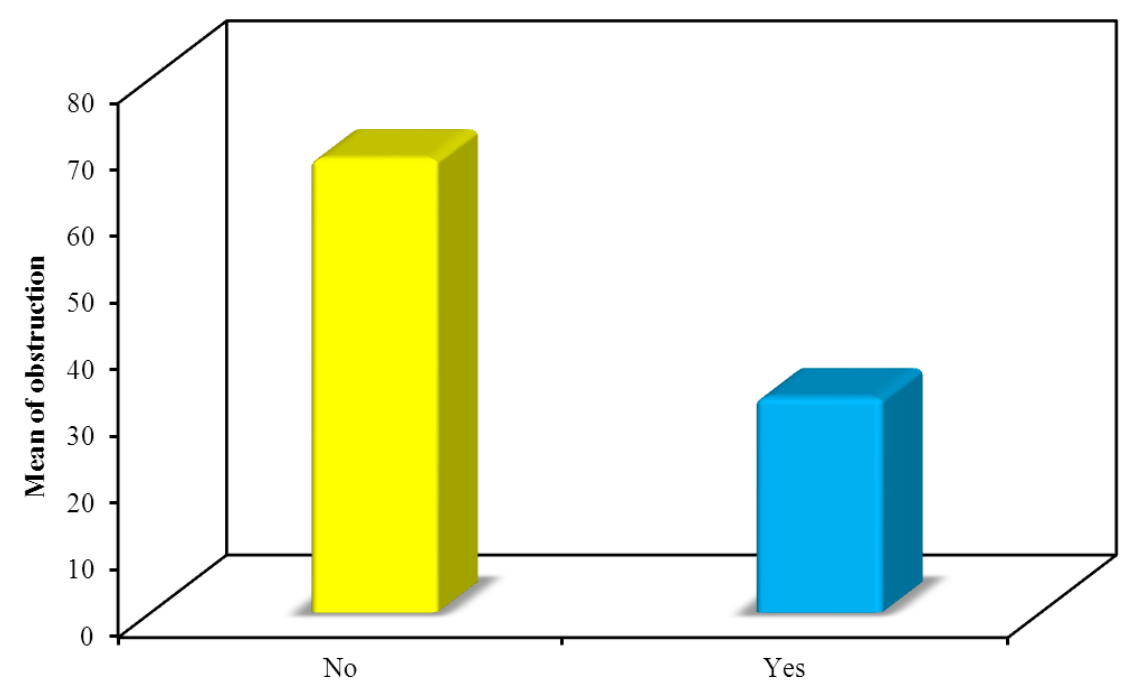

Figure 10: distribution of the studied cases according to obstruction

\section{Stress ECG data analysis:}

In present study, we assessed the myocardial bridge as regards result of stress ECG, METs, and time of exercise. We found that $17(73.9 \%)$ patients show normal stress ECG and $6(26.1 \%)$ were positive stress ECG in group (A) and $26(89.7 \%)$ patients were normal stress ECG and $3(10.3 \%)$ were positive stress ECG in group (B). $\left({ }^{\mathrm{FE}} \mathrm{p}=0.161\right)$. The mean METs in group (A) is $9.24 \pm 2.09$ ranged from 5.50 to 13.0 and in group (B) is $9.21 \pm 1.90$ ranged from 6.0 to 12.0 . ( $\mathrm{P}=0.954)$. The mean time of exercise in group A was $9.09 \pm 2.77$ minutes ranged from 4.50 to 14.0 minutes and in group B was $9.09 \pm 2.85$ minutes ranged from 5.0 to 14.0 minutes.$(\mathrm{p}=0.999)$. Relation between stress ECG and degree of systolic obstruction had statistical significance. ( $p$ $<0.002$ ), and relation between stress ECG and BMI had statistical significance ( $p<0.007)$, while relation between stress ECG and length or depth or site with no Statistical significance. Also, we found that the baseline HR, post exercise HR, PVCs, NSVTs, baseline QT interval and baseline QT dispersion had no significant statistical difference. While post exercise QT interval and post exercise QT dispersion was statistically significant factors both in our study and the other studies too. We found that the mean post exercise QT max in group A was $302.61 \pm 13.22 \mathrm{~ms}$ ranged from 280.0 to $330.0 \mathrm{~ms}$ and in group B was $291.31 \pm$ $12.0 \mathrm{~ms}$ ranged from 280.0 to $320.0 \mathrm{~ms}$ with statistically significant $(\mathrm{P}=0.002)$. The mean post exercise QT min in group A was $274.35 \pm$ $11.99 \mathrm{~ms}$ ranged from $260.0-300.0 \mathrm{~ms}$ and in group B was $268.03 \pm 10.28 \mathrm{~ms}$ ranged from
260.0 to $300.0 \mathrm{~ms}$ with statistically significant $(\mathrm{P}=0.046)$. The mean post exercise QT dispersion in group A was $28.26 \pm 7.17 \mathrm{~ms}$ ranged from 20.0 to $40.0 \mathrm{~ms}$ and in group $\mathrm{B}$ was $23.28 \pm 7.46 \mathrm{~ms}$ ranged from 8.0 to $40.0 \mathrm{~ms}$ with statistically significant $(\mathrm{P}=0.019)$.

\section{Discussion}

Myocardial bridging is a common anatomic variant on coronary CTA. In our study, the frequency of bridging on coronary CTA was higher than that reported for ICA, because of the strong reliance of the latter of the finding of systolic compression of the involved segment in establishing the diagnosis. The lower prevalence of myocardial bridges identified on invasive angiography compared to MSCT may be related to the fact that the pathognomonic "milking-phenomenon" is an indirect diagnostic criterion because invasive angiography does not allow direct visualization of the myocardium. Emerging data suggested that certain anatomic characteristics of myocardial bridges, such as length and depth, may contribute to the development of atherosclerosis and may be related to subsequent cardiac events as well to the presence of ischemia. Location and morphology (length, thickness and diameter) were detected by using MDCT. Myocardial bridges vary in size with a reported length ranging from $8-50$ $\mathrm{mm}$ by coronary CTA, and a depth between and $1-4 \mathrm{~mm}$ by coronary CTA. Longer and deeper bridges and those that exhibited greater degrees of systolic compression (> 70\%) were more common in symptomatic patients ${ }^{(18)}$. 
Myocardial bridge analysis by multidetector computed tomography and its association...

Mechanisms for Atherosclerosis in the Segment Proximal to the Bridge

Hemodynamic forces may explain atherosclerotic plaque formation at the entrance to the tunneled segment. There, the endothelium is flat, polygonal and polymorph, indicating low shear, whereas in the tunneled segment, the endothelium has a helical, spindle-shaped orientation along the course of the segment as a sign of laminar flow and high shear ${ }^{(19)}$.Low shear stress may induce the release of endothelial vasoactive agents such as endothelial nitric oxide synthase (eNOS), endothelin-1 (ET-1), and angiotensinconverting enzyme (ACE) ${ }^{(20)}$.

Their levels were significantly higher in proximal and distal segments compared with the tunneled segment. Thus, low shear stress may contribute to atherosclerotic plaque formation proximal to the bridge, whereas high shear stress may have a protective role within the tunneled segment ${ }^{(21)}$.

In addition, an increase in local wall tension and stretch may induce endothelial injury and plaque fissuring with subsequent thrombus formation in the proximal segment which is supported by autopsy and clinical observations.

\section{References}

1. Angelini $\mathbf{P}$, Velasco JA and Flamm $\mathbf{S}$ (2002): Coronary anomalies: incidence, pathophysiology and clinical relevance. Circulation, 105:2449-2454.

2. Geirnger E (1951): The mural coronary. American Heart Journal, 41(3): 359-368.

3. Gittenberger-de Groot AC, Vrancken Peeters MP et al. (1988): Epicardiumderived cells contribute a novel population to the myocardial wall and the atrioventricular cushions. Circ. Res., 82:1043-1052.

4. Reig J and Petit M (2004): Main trunk of the left coronary artery: anatomic study of the parameters of clinical interest. Clinical Anatomy, 17:6-13.

5. van Nie CJ and Vincent JG (1989): Myocardial bridges in animals. Anat. Histol. Embryol., 18:45-51.

6. Fishman MC and Chien KR (1997): Fashioning the vertebrate heart: earliest embryonic decisions. Development, 124:2099-2117.

7. Ko SM, Choi JS, Nam CW et al. (2008): Incidence and clinical significance of myocardial bridging with ECG-gated 16- row MDCT coronary angiography. Int. J. Cardiovasc. Imaging, 24:445-452.

8. La Grutta L, Runza G, Lo Re G et al. (2009): Prevalence of myocardial bridging and correlation with coronary atherosclerosis studied with 64-slice CT coronary angiography. Radiol. Med., 114:1024-1036.

9. Hongo Y, Tada H, Ito $K$ et al. (1999): Augmentation of vessel squeezing at coronary-myocardial bridge by nitroglycerin: study by quantitative coronary angiography and intravascular ultrasound. Am. Heart J., 138:345-350.

10. Kawawa Y, Ishikawa Y, Gomi T et al. (2007): Detection of myocardial bridge and evaluation of its anatomical properties by coronary multislice spiral computed tomography. Eur. J. Radiol., 61:130-138.

11. Kramer JR, Kitazume H, Proudfit WL et al. (1982): Clinical significance of isolated coronary bridges: benign and frequent condition involving the left anterior descending artery. Am. Heart J., 103:283-8.

12. Faruqui AM, Maloy WC, Felner JM et al. (1978): Symptomatic myocardial bridging of coronary artery. Am. J. Cardiol., 41:13051310.

13. Achrafi H (1992): Hypertrophic cardiomyopathy and myocardial bridging. International Journal of Cardiology, 37(1): 111-112.

14. Schwarz ER, Klues HG, vom Dahl J et al. (1996): Functional, angiographic and intracoronary Doppler flow characteristics in symptomatic patients with myocardial bridging: effect of short-term intravenous beta-blocker medication. J. Am. Coll. Cardiol., 27:1637-1645.

15. Doshi AA, Orsini AR, Mazzaferri EL et al. (2007): Drug eluting stent implantation for the treatment of symptomatic myocardial bridging is associated with favorable periprocedural results and short-term outcomes. Int. J. Cardiol., 118: 87-95.

16. Kim PJ, Hur G, Kim SY et al. (2009): Frequency of myocardial bridges and dynamic compression of epicardial coronary arteries: a comparison between computed tomography and invasive coronary angiography. Circulation, 119:1408-1416.

17. Flynn MS, Kern MJ, Aguirre FV et al. (1994): Intramyocardial muscle bridging of the coronary artery - an examination of a diastolic - spike and domell pattern of 
coronary flow velocity. Cathet. Cardiovasc. Diagn., 32:36-39.

18. Mookadam F, Green J, Holmes D et al. (2009): Clinical relevance of myocardial bridging severity: single center experience. Eur. J. Clin. Invest., 39:110-115.

19. Ishii T, Asuwa N, Masuda S et al. (1998): The effects of a myocardial bridge on coronary atherosclerosis and ischemia. J. Pathol., 185:4-194.
20. Masuda T, Ishikawa Y, Akasaka Y et al. (2001): The effect of myocardial bridging of the coronary artery on vasoactive agents and atherosclerosis localization. J. Pathol., 193:408-414.

21. Klues HG, Schwarz ER, vom Dahl J et al. (1997): Disturbed intracoronary hemodynamics in myocardial bridging. Early normalization by intracoronary stent placement. Circulation, 96:2905-2913. 